Article

\title{
New directions in sensor research: a bibliometric analysis for detecting emerging research fields and new technological trajectories
}

\author{
Mario Coccia \\ CNR -- National Research Council of Italy, Research Institute on Sustainable Economic Growth \\ Collegio Carlo Alberto, Via Real Collegio, 30-10024 Moncalieri (Torino), Italy \\ * Correspondence: mario.coccia@cnr.it; Tel.: +39-011 6824915
}

\section{Saeed Roshani}

Allameh Tabataba'i University, Faculty of Management and Accounting, Department of Industrial Management, Tehran, Iran E-mail: Roshani@atu.ac.ir

\section{Melika Mosleh}

Birmingham Business School, College of Social Sciences, University of Birmingham, UK

E-mail: mxm1219@alumni.bham.ac.uk

\begin{abstract}
The fundamental question in the field of sensor research is new directions of scientific fields, which play a vital role in the progress of science and technology. This study confronts this question here by developing a bibliometric analysis, which endeavors to explain the evolution of sensor research and new technologies that are critical to science and society. The database of Scopus concerning scientific documents and patents is used for statistical and computational analyses in these topics. Results suggest that emerging technological trajectories in sensors are wireless sensor networks, wearable sensors and biosensors. Main characteristics of these growing research fields and technologies in sensors are described for fruitful implications of research and innovation policy directed to science advances and technological change in society.
\end{abstract}

Keywords:

Sensor research, Research fields, Evolution of science, Dynamics of science, Scientific development, Technological trajectories, Biosensors, Wearable sensors, Wireless sensor network. 


\section{Introduction}

The evolution of sensor research and technology has critical aspects to science and human society (Rao et al., 2018; Sensors, 1992; Coccia and Bellitto, 2018). These topics of "The science of science" can clarify the driving factors of the evolution of science in sensors directed to support scientific discoveries and technological advances in society (Fortunato et al., 2018; Coccia 2020; Sun et al., 2013). First of all, a brief background of vital concepts in sensors is useful to clarify the study design here. A broad concept of sensor is a device, module or subsystem having the goal to detect events or changes in specific environment and send the information to other interrelated technological devises, such as a computer processor (Göpel et al., 1989; National Research Council, 1995; Rao et al., 2018). Sensors are technologies ${ }^{1}$ associated with different technologies, generating complex interactions in a perspective of host-parasite technological systems (cf., Coccia, 2018a, 2019, 2019a; Coccia and Watts, 2020). In particular, sensor system can be considered a parasite technology of other technological systems (Coccia, 2019; 2019a; Coccia and Watts, 2020). The parasitic technologies of sensors are systems that interact with the ecological system of the host (or master) technology (Elsisi et al., 2021; Kholod et al., 2021; Pereira et al., 2017). For instance, the sensors of inertial measuring unit and global positioning system are parasite technologies when installed in wearable (host) technology of consumer sports (Aroganam et al., 2019). Other types of parasite technologies of sensors are temperature sensors, proximity sensors, pressure sensors, etc. (Soy and Toy, 2021). In general, sensor technologies have parasitic relationships and multimode interactions with other technologies that support continuous evolutionary patterns of technological trajectories (Hudec et al., 2021; Suresh Kumar et al., 2021, Tatiparthi et al., 2021; cf., Coccia and Watts, 2020; Coccia, 2019, 2019a; Coccia, 2019b; 2019c; Coccia, 2020a; 2020c, 2020d; Dosi, 1988; Nelson, 2008). In fact, the progress in science and technology (e.g., artificial intelligence, solid-state electronics, optical computing and information processing, microelectromechanical systems, etc.) is supporting new types of sensors having improved performance for manifold needs of human activity (National Research Council, 1995). One of the most important advances in sensor technology is the development of smart or intelligent sensors, driven by convergence of technologies in machine learning, ubiquitous computing, etc. (Liu et al., 2021; Fan et al., 2021; Hussain, 2020; Rahimunnisa et al., 2021; Seymour et al., 2021; Yagoob and Younis, 2021; Soy and Toy, 2021; Suresh Kumar and Krishnamoorthi, 2021; Wang et al., 2021; Zhang et al., 2021). New studies show that smart sensors are crucial and integral elements in the Internet of Things (Alharbi et al., 2021; Banerjee et al., 2021, Davoli et al., 2021; Del-Vallesoto et al., 2021; Jo et al., 2021; Pal et al., 2020; Wang et al., 2021a). In addition, innovations in information and communication technologies, associated with the internet of things, have the potential to generate new sensors having applications in different fields (Abidoye and Kabaso, 2021; Coccia and Watts, 2020; Coccia, 2020b; Fang, 2021; Li et al., 2021). Hence, sensor research and technologies have a continuous evolution by the interaction with different and new research fields and technologies, generating innovative devices for sensing that are more and more networked and with aspects of artificial intelligence (Coccia, 2020d).

The main goal of this article is to analyze sensor research to explain the growth and main applications of new technologies for the technological and social change. Results here can clarify the dynamics of science in sensors that can be useful to policymakers for allocating resources and planning scientific and

\footnotetext{
${ }^{1}$ Technology is a complex system, composed of more than one entity or sub-system of technologies and a relationship that holds between each entity and at least one other entity in the system for achieving specific goals (Coccia and Watts, 2020).
} 
technological development having positive societal impact. This study is part of a large body of research on the evolution of science and technology that endeavors to explain how research fields and new technologies emerge and evolve in basic and applied sciences (Coccia, 2015, 2017a, 2017b, 2018, 2018, 2019b, 2020; Kashani \& Roshani, 2019; Roshani et al., 2021; Scharnhorst et al., 2012; Sun et al., 2013).

\section{Materials and Methods}

\subsection{Study design for technological trajectories}

- Sources and Sample

The study uses datasets of Scopus (2021). In particular, the window of "Search documents" in Scopus (2021) database is used to identify scientific documents having in title, abstract or keywords of articles and patents the term "sensors". Scientific products and patents are the basic units for technology and scientific analyses to explain the evolution of science and technology in the field of sensors with fruitful policy implications.

\section{- Measures}

- Number of articles and all scientific products in "sensors" (conference papers, conference reviews, book chapters, short surveys, letters, etc.), 1955-2020 period.

Data under study here are 1,217,947 document results downloaded in April 2021. The scientific evolution of sensors and specific keywords, measured with the number of articles and other scientific products, can show the dynamics of sensor research.

Additional measure for the analysis of the evolution of sensor technology is:

- Number of patents, $1952-2020$ period

Patents indicate inventions, and this study analyzes 1,226,074 units over the 1952-2020 period recorded for the field of sensors and its sub-fields.

- Specification of the model and data analysis procedure

The tool "Search documents" in Scopus (2021) provides keywords and time series of documents with the highest frequency in sensor research. After that, sensor technologies with the highest number of documents in the list of keywords have been selected, i.e.,:

- wireless sensor networks

- fiber optic sensors

- chemical sensors

- remote sensing

- biosensor

- wearable sensors

- image sensors

- wireless sensor

- optical sensors

- glucose sensors

Each of this keyword is inserted in the window "search documents" to detect the specific time series that 
is used for a comparative analysis between sensor technologies in the list just mentioned to analyze the rate of growth and, as a consequence, new directions in sensor research. The study applies the model by Sahal (1981) for scientific and technology analysis of time series in sensor.

Two models are specified as follows.

Firstly,

$\log y_{i, t}=a+b$ time $+u_{t}$

$y_{t}$ is the dependent variable of scientific products or patents.

$a$ is a constant; $b$ is the coefficient of regression; The parameters $a$ and $b$ are unknown and are estimated using the sample of data.

$\log$ has base $e=2.7182818$; $t=$ time; $u_{t}=$ error term in equation.

Secondly, if we consider the ratio:

$$
\delta_{i, t}=\frac{\text { number of publications (or patents) in the subfield } i \text { of sensors at } t}{\text { Total number of publications (or patents) at } t}
$$

The specification of the model is:

$\log \delta_{i, t}=a^{\prime}+b^{\prime}$ time $+\varepsilon t$

The equation [2] also has $a^{\prime}=$ constant; $b^{\prime}=$ coefficient of regression $\left(a^{\prime}\right.$ and $b^{\prime}$ are the parameters to be estimated); $t=$ time; $\varepsilon_{t}=$ error term in equation.

The relationships under study here for scientific and technology analysis are investigated using the Ordinary Least Squares (OLS) method for estimating the unknown parameters in regression models [1] and [2]. Statistical analyses are performed with the IBM SPSS Statistics 26 ®.

\subsection{Technological analysis within research fields of sensors to detect technological characteristics and applications}

- Research settings

The methodology here has the purpose to investigate the structure of emerging research fields in sensor technology, detected with previous statistical analysis by the highest coefficients of regression of estimated relationships based on publication and patent data (equations [1] and[2]); in particular, the magnitude of coefficients of regression is a proxy of high evolutionary growth of sensor research over time. Emerging research fields under study here, having the highest coefficients of regression, are given by:

․ wireless sensor network. A wireless sensor network is a group of objects that transfer the gathered data through multiple nodes and wireless infrastructure to cooperatively sense and control the environment (Yick, 2008). These devices are positioned in large numbers, so they need the ability to assist each other to transfer data back to a centralized collection point (Rajaravivarma, 2003).

wearable sensors. Wearable sensors are integrated into wearable objects attached to the body in health monitoring or physically relevant data collection. They have diagnostic and monitoring applications, including physiological and biochemical sensing and motion sensing (Teng, 2008). Wearable sensor adaptation has involved miniaturizing sensing technologies, making them 
conformal and flexible, and developing companion software that increases the value of the measured data (Heikenfeld, 2018).

ㅁiosensors. A biosensor is an analytical device that measures biological or chemical sensing elements and reactions. They are generally employed in monitoring, pollutants detection, and biomarkers discovery (Kissinger, 2005). They restrain biology's great sensitivity and specificity in intersection with physicochemical transducers to provide detailed and bioanalytical measurements with easyto-use and straightforward formats (Turner, 2013).

This section applies Natural Language Processing (NLP) to demonstrate common research themes in emerging subfields of the sensor, just mentioned (i.e., wireless sensor network, wearable sensors and biosensors). In the document type section of the Scopus dataset (Scopus, 2021a), the data of conference paper, article, conference review, and review have been collected. Among statistical algorithms, topic modelling as a text-mining tool can help to discover and organize latent topics. This modelling allows us to create an extensive text body's semantic structures through various disciplines correlations (Jiang et al., 2016). We implemented the Latent Dirichlet Allocation ( LDA ) as an unsupervised approach for topic modelling (i.e., machine learning -LDA) that attract popularity in textual data processing due to its ability to reduce the bias and increase the accuracy for literature investigation (Blei et al., 2003). Moreover, we used java implementation of this model with the name MALLET (McCallum, 2002). In this study, we used the Python programming language for building a topic model. The methodology has been accomplished in three steps: (1) data gathering and text pre-processing, (2) topic construction, and (3) investigation, which are explained in more details.

- Sources of data, sample and measures of computational analyses

This study, as said, uses data from Scopus (2021a). According to search procedures, we have obtained:

- 1,989 publications in wireless sensor networks published from 1989 to the end of 2020, including keywords in articles' keywords, abstract and title.

○ 71,780 articles in wearable sensors published from 1998 to 2020.

○ 66,996 documents in biosensor published from 1970 to 2020.

After an initial review of these articles, the abstracts were used to input the LDA technique to explore topics under study. Measures are similar and described in previous section.

- Topic modelling and data analysis procedure

- Step 1: data gathering and text pre-processing

This study employed data from the Scopus (2021) database. For collecting the related documents, we used the search string TITLE-ABS-KEY("wearable sensor") for wearable sensor papers, TITLE-ABSKEY("Biosensor") for Biosensor papers, and TITLE-ABS-KEY ("Wireless sensor network") for Wireless sensor network documents. All publications have been collected until 2020, and for increasing the accuracy of data, this study has limited the records to conference papers, article, conference reviews, and reviews in English. 
Secondly, for textual data pre-processing, we conducted a topic modelling analysis using Python 3.7.7 version programming language to first concatenating all abstracts of publications and then concatenating them into one string set for each field. We created a corpus of the respective field documents by which the model learns the 'topics'. The data are pre-processed prior to the topic modelling using GenSim library (Rehurek, 2010) to convert each publication's abstract into a bag-ofwords representation. We consider each word as a token and then eliminated words in a stopword list provided in the MALLET software (McCallum, 2002). Then, words with a low frequency, fewer than three characters have got removed. We exerted the Tokenization technique by splitting the text into a set of words, punctuation removal, adjusting the terms with higher cases into lowercase. Aside from those processes, we implement lemmatization to assimilate all the verbs in various tenses to present tenses and modified them to the first person. In the end, we removed all terms that appear fewer than ten times across all documents, or that appear in more than 70 percent of records.

- Step 2: topic construction

We can assume a topic as a probability distribution over a term. Those vocabularies with a high probability of occurrence in the same topic are more likely to appear frequently in the same documents simultaneously. For constructing the topic, we started training the model using MALLET, a Java-based package used for statistical NLP developed by McCullum (2002) to build a Latent Dirichlet Allocation model (LDA). This model requires a fixed number of topics that is not specified accurately for a corpus. Accordingly, we chose an optimal number of topics for implementing the topic modelling technique following the study by Mifrah and Benlahmar (2020). In this respect, we calculated the topic coherence score for each number of topics to identify the most efficient one. We used the $C_{-} v$ coherence measure to retrieve co-occurrence counts of respective word sets based on the sliding window size. We calculated the normalized pointwise mutual information (NPMI) for every top word to every top word to extract a set of vectors for each top word. Afterwards, we measured the similarity between the top words sum vector and each top word vector in one-set segmentation. We utilized cosine similarity to calculate the coherence score based on an arithmetic mean of all similarities (Mifrah and Benlahmar, 2020). We calculated the coherence of a couple of models through different numbers of topics according to the approach of Röder (2015) to identify the best number of topics for our model applied in the present study. Figure 1 demonstrates the coherence score of the model through the different numbers of topics. For wearable sensors, results show that the highest coherence value (i.e., 0.5546) occurs in topic number 22 , for biosensors, the highest coherence value (i.e., 0.5687 ) occurs in topic number 32 , and for wireless sensor network, the greatest coherence value (i.e., 0.5260) stands for topic number 38.
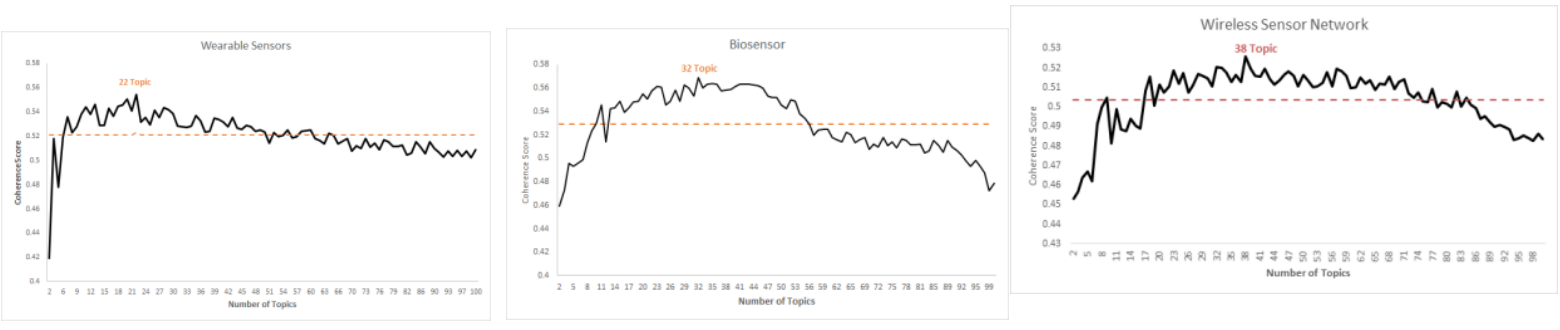

Figure 1. Topic coherence score with a different number of topics in wearable sensor, biosensor, and wireless network sensor with the sliding window size of 100 .

\section{- Step 3: investigation}

In this step, the study here investigated topics of the emerging research fields in sensor technology described before: wireless sensor network; wearable sensors and biosensors. This section presents 
topic modeling findings using a world-cloud demonstration in which the size of each word in a specific topic is according to its frequency in that topic. Afterward, we classified all the topics of each field into two categories: technological characteristics and applications. In the second part of the results, trend analysis was conducted separately to demonstrate their evolutionary growth based on the popularity of topics over time. Evolutionary growth of topics within each research field under study (wireless sensor network, wearable sensors, and biosensors) has been categorized in Positive Evolutionary Growth, Stable Evolutionary Growth, and Negative Evolutionary Growth to assess the topic trend analysis for the classification of each emerging subfields of the sensor. In particular,

- 'Positive Evolutionary Growth indicates that the topic popularity has been increasing, and the occurrence frequency of the topic words has been elevating.

- 'Stable Evolutionary Growth indicates that the topic popularity has been fluctuating and doesn't follow a rising or falling trend. It means that the occurrence frequency of the words in the topic has stable evolution.

- 'Negative Evolutionary Growth indicates that the topic popularity has been decreasing, and the occurrence frequency of the topic words has been faced reduction.

\section{Results and Discussion}

\subsection{Growth of research fields in sensors}

The parametric estimates of models [1-2], based on scientific production, are presented in Table 1. In a majority of cases, the significance of the coefficients of regression and the explanatory power of the equations has $p$-value $<.001$. The $\mathrm{R}^{2}$ values are high and in general the models explain more than $80 \%$ variance in the data. 
Table 1 - Estimated relationships of scientific production in research fields of sensors as a function of time

Dependent variable: scientific products concerning scientific fields in sensors

\begin{tabular}{|c|c|c|c|c|c|}
\hline Research fields & Coefficient $b_{1}$ & Constant a & F & $R^{2}$ & $N$, period \\
\hline Wireless Sensor Networks, $\log y_{i, t}$ & $.35^{* * *}$ & $-695.45^{* * *}$ & $141.64 * * *$ & .85 & $N=27(1989-2020)$ \\
\hline $\log \delta_{i, t}$ & $.24 * * *$ & $-490.02^{* * *}$ & $140.46^{* * *}$ & .82 & \\
\hline Fiber Optic Sensor, $\log y_{i, t}$ & $.17 * * *$ & $-324.33 * * *$ & $432.74 * * *$ & .90 & $N=51(1965-2020)$ \\
\hline $\log \delta_{i, t}$ & $.05^{* * *}$ & $-100.24 * * *$ & $38.17 * * *$ & .43 & \\
\hline Chemical Sensor, $\log y_{i, t}$ & $.17 * * *$ & $-339.06 * * *$ & $345.42 * * *$ & .89 & $N=46(1968-2020)$ \\
\hline $\log \delta_{i, t}$ & $.06 * * *$ & $-130.48 * * *$ & $54.10^{* * *}$ & .55 & \\
\hline Remote sensing, $\log y_{i, t}$ & $.13 * * *$ & $-241.34 * * *$ & $304.89 * * *$ & .84 & $N=60(1956-2020)$ \\
\hline $\log \delta_{i, t}$ & -.002 & 1.96 & .18 & .003 & \\
\hline Biosensors, $\log y_{i, t}$ & $.18^{* * *}$ & $-343.25^{* * *}$ & $255.47 * * *$ & .86 & $N=43(1970-2020)$ \\
\hline $\log \delta_{i, t}$ & $.07 * * *$ & $-137.53^{* * *}$ & $47.34 * * *$ & .53 & \\
\hline Wearable sensors, $\log y_{i, t}$ & $.30 * * *$ & $-598.27 * * *$ & $766.26^{* * *}$ & .97 & $N=22(1998-2020)$ \\
\hline $\log \delta_{i, t}$ & $.21 * * *$ & $-421.51 * * *$ & $406.37 * * *$ & .95 & \\
\hline Image sensors, $\log y_{i, t}$ & $.12 * * *$ & $-223.08^{* * *}$ & $236.66^{* * *}$ & .81 & $N=55(1964-2020)$ \\
\hline $\log \delta_{i, t}$ & -.004 & 3.95 & .48 & .009 & \\
\hline Wireless sensor, $\log y_{i, t}$ & $.34 * * *$ & $-679.77 * * *$ & $221.60^{* * *}$ & .88 & $N=30(1984-2020)$ \\
\hline $\log \delta_{i, t}$ & $.24 * * *$ & $-490.02 * * *$ & $140.46^{* * *}$ & .83 & \\
\hline Optical sensors, $\log y_{i, t}$ & $.13^{* * *}$ & $-255.65^{* * *}$ & $562.65^{* * *}$ & .91 & $N=56(1962-2020)$ \\
\hline $\log \delta_{i, t}$ & $.008^{*}$ & $-20.44 *$ & $3.64 *$ & .06 & \\
\hline Glucose sensors, $\log y_{i, t}$ & $.12^{* * *}$ & $-243.19 * * *$ & $584.69 * * *$ & .93 & $N=47(1973-2020)$ \\
\hline $\log \delta_{i, t}$ & $.02 * * *$ & $-43.14 * * *$ & $15.72^{* * *}$ & .26 & \\
\hline
\end{tabular}

Note: Explanatory variable is time in years. $N$ is the number of observations from the specified period (the first year indicates the first paper recorded, the second year is 2020 because 2021 is still ongoing). *** significant at $1 \%$; ${ }^{* *}$ significant at $1 \%,{ }^{*}$ significant at $5 \% . F$ is the ratio of the variance explained by the model to the unexplained variance; $R^{2}$ is the coefficient of determination adj. 
Table 2 shows the parametric estimates of models [1-2] based on patents. Table 2 also reveals that in a majority of cases, the significance of the coefficients of regression and the explanatory power of the equations has $p$-value<.001, except model [2] for remote sensing. The $\mathrm{R}^{2}$ values are also high and in a majority of cases the models explain more than $70 \%$ variance in the data.

Table 2 - Estimated relationships of patents in research fields of sensors as a function of time

\begin{tabular}{|c|c|c|c|c|c|}
\hline \multicolumn{6}{|c|}{ Dependent variable: patents concerning scientific fields in sensors } \\
\hline Research fields & Coefficient $b_{1}$ & Constant a & F & $R^{2}$ & $N$, period \\
\hline Wireless Sensor Networks, $\log p y_{i, t}$ & $.30 * * *$ & $-591.58^{* * *}$ & $60.02 * * *$ & .77 & $N=19(2000-2020)$ \\
\hline $\log p \delta_{i, t}$ & $.21 * * *$ & $-430.12^{* * *}$ & $41.72^{* * *}$ & .70 & \\
\hline Fiber Optic Sensor, $\log p y_{i, t}$ & $.14 * * *$ & $-272.48^{* * *}$ & $291.16^{* * *}$ & .86 & $N=50(1971-2020)$ \\
\hline $\log p \delta_{i, t}$ & $.03 * * *$ & $-59.57 * * *$ & $12.64^{* * *}$ & .21 & \\
\hline Chemical Sensor, $\log p y_{i, t}$ & $.16^{* * *}$ & $-314.77 * * *$ & $1293.12^{* * *}$ & .96 & $N=54(1965-2020)$ \\
\hline $\log p \delta_{i, t}$ & $.04 * * *$ & $-92.14 * * *$ & $92.52^{* * *}$ & .64 & \\
\hline Remote sensing, $\log p y_{i, t}$ & $.13^{* * *}$ & $-240.97 * * *$ & $304.30 * * *$ & .84 & $N=60(1956-2020)$ \\
\hline $\log p \delta_{i, t}$ & -.002 & 2.50 & .24 & .004 & \\
\hline Biosensors, $\log p y_{i, t}$ & $.20 * * *$ & $-383.42^{* * *}$ & $255.38^{* * *}$ & .86 & $N=43(1978-2020)$ \\
\hline $\log p \delta_{i, t}$ & $.09 * * *$ & $-181.04 * * *$ & $59.81 * * *$ & .59 & \\
\hline Wearable sensors, $\log p y_{i, t}$ & $.25^{* * *}$ & $-492.18^{* * *}$ & $283.88^{* * *}$ & .93 & $N=24(1984-2020)$ \\
\hline $\log p \delta_{i, t}$ & $.15^{* * *}$ & $-304.52^{* * *}$ & $98.78^{* * *}$ & .81 & \\
\hline Image sensors, $\log p y_{i, t}$ & $.18^{* * *}$ & $-340.36^{* * *}$ & $438.04 * * *$ & .89 & $N=55(1964-2020)$ \\
\hline $\log p \delta_{i, t}$ & .06 & -112.64 & 68.68 & .56 & \\
\hline Wireless sensor, $\log p y_{i, t}$ & $.22 * * *$ & $-425.83^{* * *}$ & $837.44 * * *$ & .96 & $N=39(1974-2020)$ \\
\hline $\log p \delta_{i, t}$ & $.11 * * *$ & $-232.03^{* * *}$ & $268.89 * * *$ & .88 & \\
\hline Optical sensors, $\log p y_{i, t}$ & $.16^{* * *}$ & $-313.61 * * *$ & $372.72 * * *$ & .87 & $N=59(1960-2020)$ \\
\hline $\log p \delta_{i, t}$ & $.03 * * *$ & $-65.57 * * *$ & $29.65^{* * *}$ & .34 & \\
\hline Glucose sensors, $\log p y_{i, t}$ & $.15^{* * *}$ & $-300.56^{* * *}$ & $663.05^{* * *}$ & .94 & $N=46(1974-2020)$ \\
\hline $\log p \delta_{i, t}$ & $0.05^{* * *}$ & $-100.51^{* * *}$ & $84.23^{* * *}$ & .65 & \\
\hline
\end{tabular}

Note: Explanatory variable is time in years. $N$ is the number of observations from the specified period (the first year indicates the first paper recorded, the second year is 2020 because 2021 is still ongoing). ${ }^{* * *}$ significant at $1 \%$; ${ }^{* *}$ significant at $1 \%,{ }^{*}$ significant at $5 \%$. $F$ is the ratio of the variance explained by the model to the unexplained variance; $R^{2}$ is the coefficient of determination adj. 
Table 3, using the coefficients of regression of models calculated in table 1 and 2 (trends are displayed in Figure 2 and 3), suggests that the emerging research fields in sensors are:

○ wireless sensor networks

- wearable sensors

o and biosensors.

Results also suggest that wireless sensors, a restriction of wireless sensor networks, has a high evolutionary growth in the field of sensor technology. All these research fields are the younger ones among research fields in sensors. This result is consistent with studies by Coccia $(2018,2020)$ that higher growth rates of scientific production are in new research fields rather than old ones.

Table 3 - Evolutionary growth of scientific fields in sensor technology based on coefficients of regression considering the number of publications and patents over time, and their scientific age from the first scientific products to the year 2020

\begin{tabular}{lcclcc}
\hline & $\begin{array}{c}\text { Coefficient of } \\
\text { Publication }\end{array}$ & Age & Research fields & $\begin{array}{c}\text { Coefficient of } \\
\text { patents }\end{array}$ & Age \\
\hline Wireless Sensor Networks & .35 & 31 & Wireless Sensor Networks & .30 & 31 \\
Wireless sensor & .34 & 36 & Wearable sensors & .25 & 22 \\
Wearable sensors & .30 & 22 & Wireless sensor & .22 & 36 \\
Biosensors & .18 & 50 & Biosensors & .20 & 50 \\
Fiber Optic Sensor & .17 & 55 & Image sensors & .18 & 56 \\
Chemical Sensor & .17 & 52 & Chemical Sensor & .16 & 52 \\
Remote sensing & .13 & 64 & Optical sensors & .16 & 58 \\
Optical sensors & .13 & 58 & Glucose sensors & .15 & 47 \\
Image sensors & .12 & 56 & Fiber Optic Sensor & .14 & 55 \\
Glucose sensors & .12 & 47 & Remote sensing & .13 & 64 \\
\hline
\end{tabular}

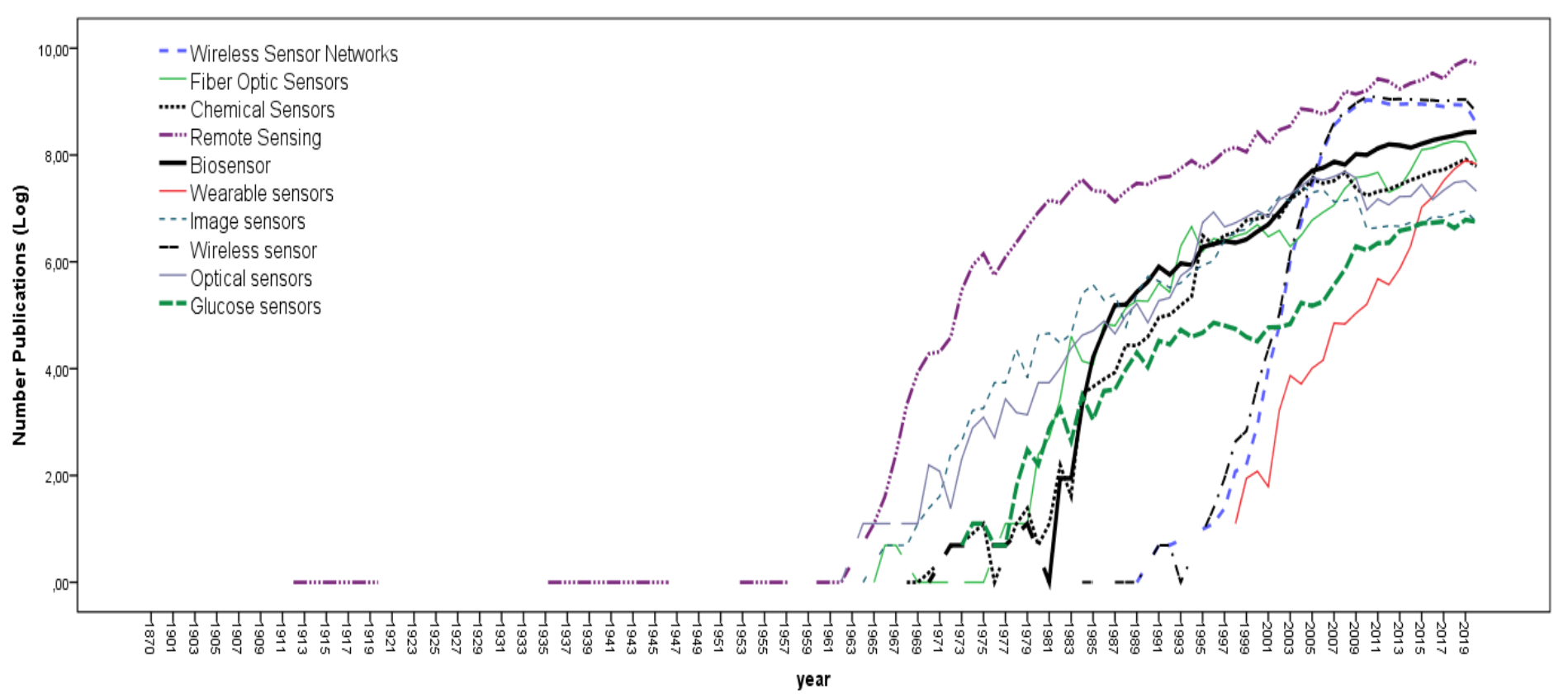

Figure 2. Trends of research fields in sensors using scientific production (log scale) 


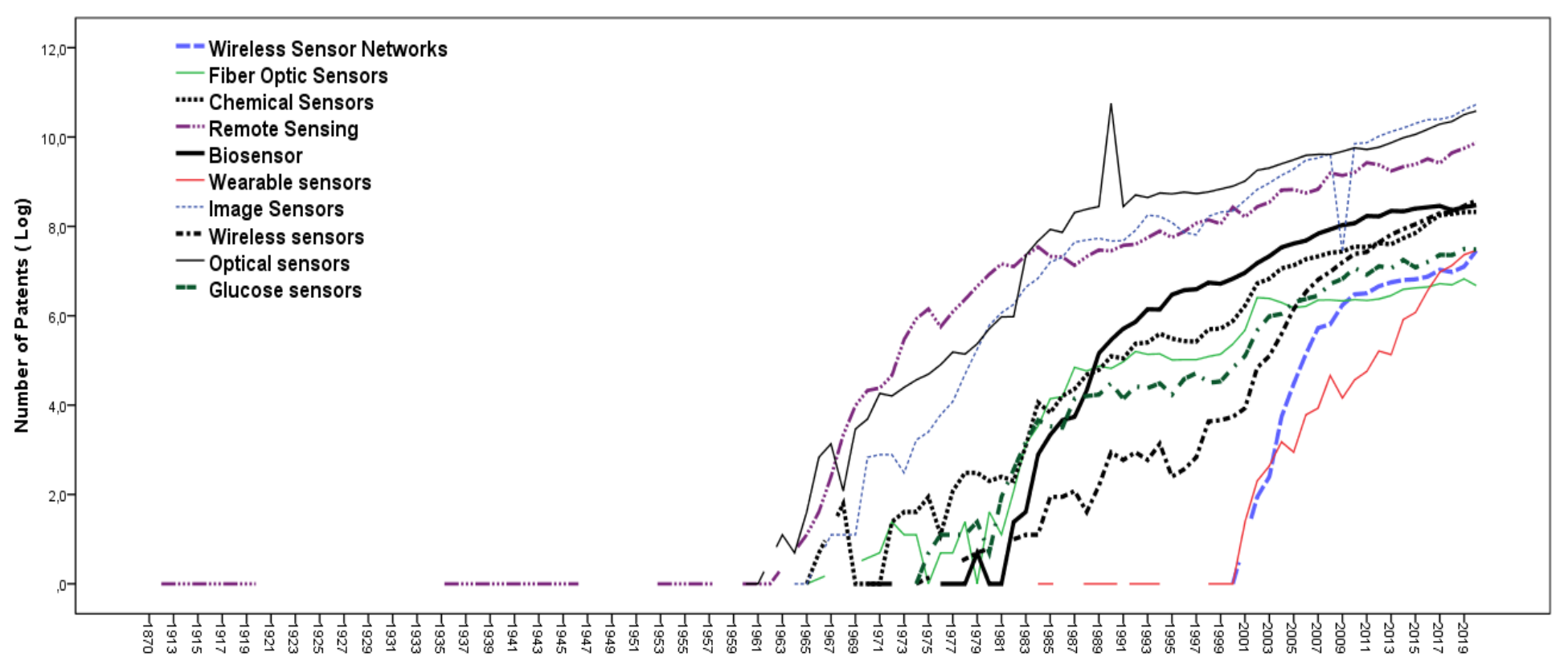

Figure 3. Technological trajectories of sensor using patents (log scale)

The next section investigates these research fields and technologies to clarify their structure and drivers in science dynamics to detect critical technological characteristics and applications for progress in society and society.

\subsection{Structure, characteristics, and applications of critical research fields in sensors}

The results of topic modelling analysis demonstrate the top 15 high-frequency terms in each topic. These topics contain the words reflecting the content and terms of documents with the highest score. The topics are related to significant issues in each growing subfield in sensor technology. We illustrated 38 topics in wireless sensor network, 22 topics in wearable sensors, and 32 topics in biosensors through a worldcloud analysis; the size of each word indicates comparatively the frequency weight of a term in a specific case. The larger the word, the higher the frequency stands in the parent topic. Accordingly, this visualization can reflect the brief information of each topic and partially explains the included documents. Ultimately, this study analyzes and explores the evolution of these topics over time. Topic modeling analysis can also demonstrate the increasing or decreasing popularity of topics, which can better explain how a field of research has been changing over time. We normalized the proportion of each topic per year and obtained the annual trends.

○ wireless sensor network

Figure 4 shows the 20 most frequent words that appeared in publications on wireless sensor network. Our results show that the terms "network", "node", "wireless", and "energy" have been used more than 100,000 times across the corpus. Each word, according to its similarity regarding the co-occurrence, leads to topics creation. 


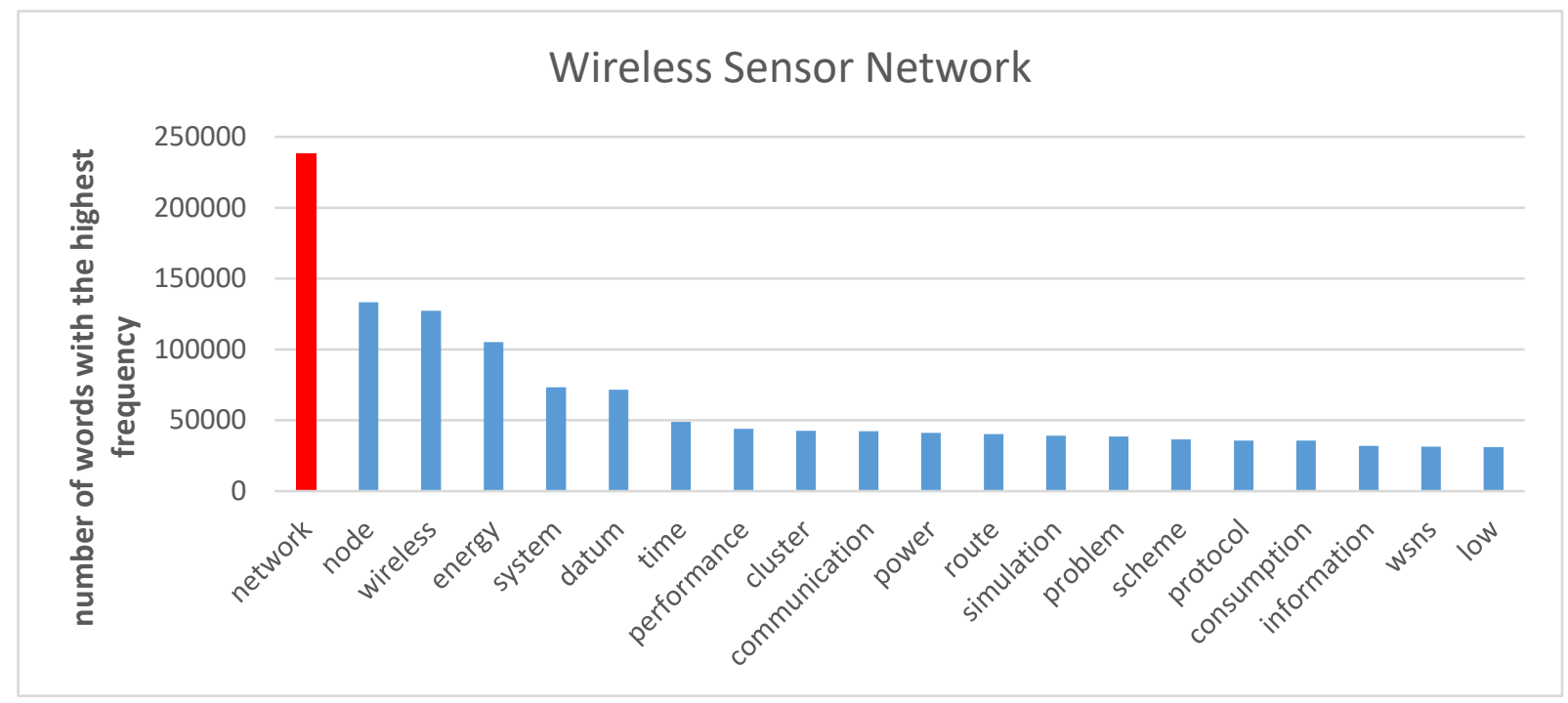

Figure 4. The highest frequent words in the wireless sensor network documents

Figure 5 shows the topic's classification of the wireless sensor network. The largest words of each class represent the content of the topic documents. Figure 5 of Word-Cloud analysis suggests information about technological characteristics and applications of wireless network sensor. In particular, main technological characteristics of wireless sensor networks are (from Figure 5):

- Internet of things

- network optimization

- data security

- monitoring system

- optimization

- technical infrastructure

Instead, the main application characteristics of wireless sensor networks are (from Figure 5):

- environmental monitoring,

- communication systems

- energy

- smart vehicles

- control systems

- healthcare 

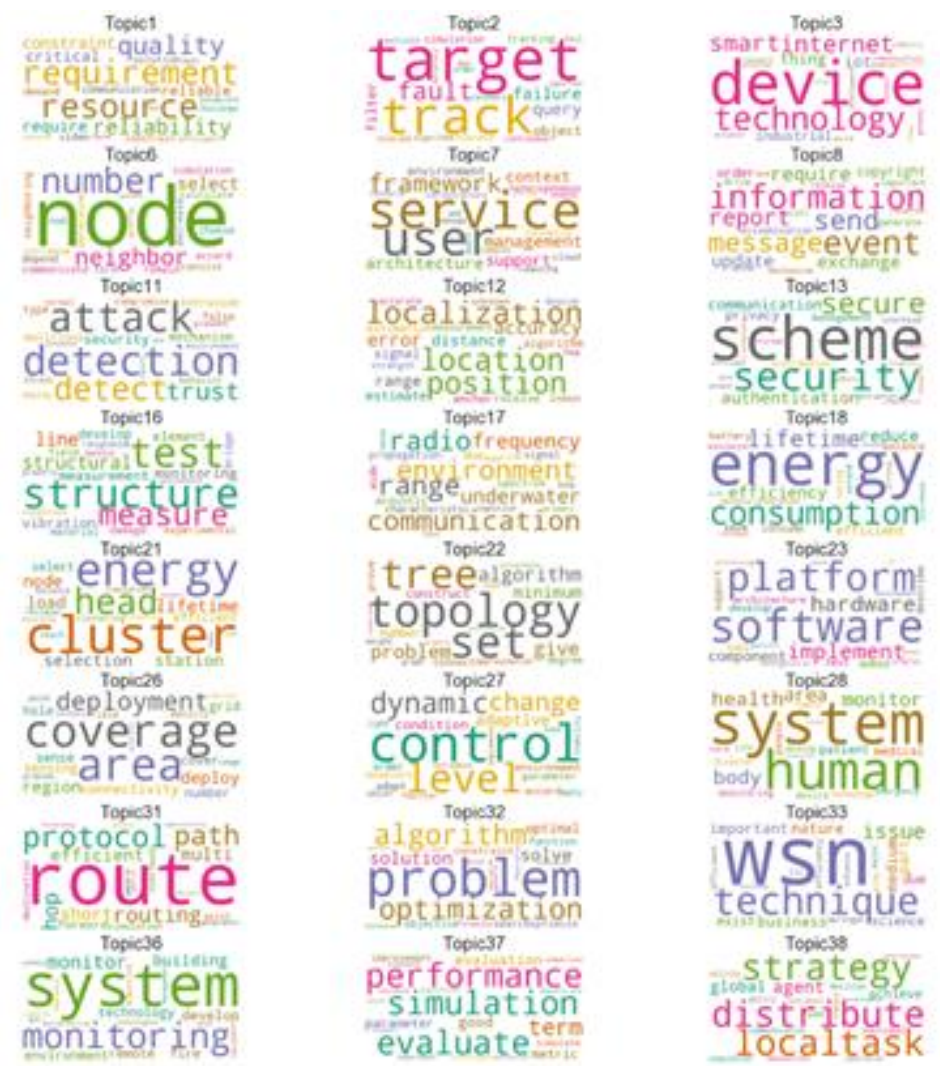
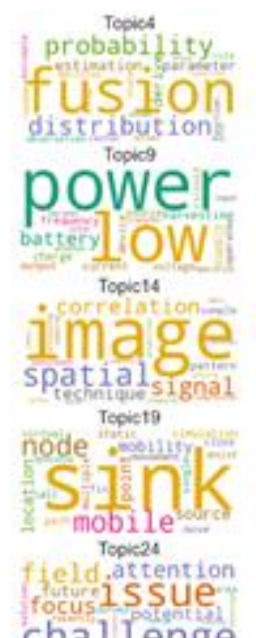

challenge

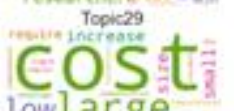

lowlarge

traffic Topit $^{2}$

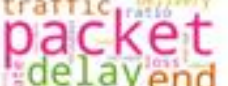

delayend

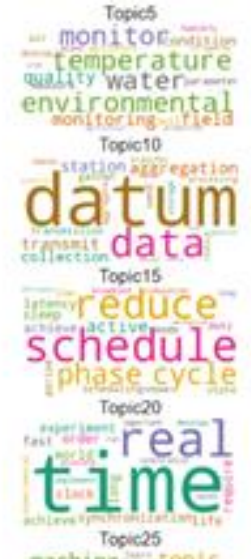

system Topicaso

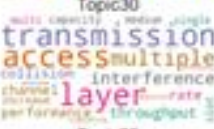

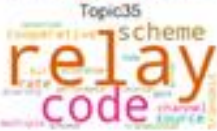

Figure 5. World-Cloud of wireless sensor network

Table 4 shows the evolutionary growth of topics in wireless network sensor. From this classification, it can be concluded that the studies of smart sensors associated with the Internet of things are growing; the studies of environmental monitoring and health care evolutionary level are also increasing over time. 
Table 4. Dynamics of trends in wireless sensor network using trend analysis

\begin{tabular}{ll}
\hline Number of Topics \\
\hline Positive Evolutionary Growth & 3 (smart device, internet of things, etc.), 5(environmental, water, \\
& temperature, monitor, etc.), 24(future, potential, challenge, etc.), \\
& 28(system, human, health, etc.), 33(WSN, technique, business, etc.) \\
Stable Evolutionary Growth & distribution, etc.), 6( node, neighbor, etc.), 7(service framework, \\
& architecture, etc.), 8(information, report, etc.), 9(power, low, battery, \\
& etc.), 10(datum, aggregation, transmit, etc.),11(attack, detection, \\
& trust, etc.), 12(localization, position, location, etc.), 13(scheme, \\
& security, communication, etc.), 14(image, signal, etc.), 15(schedule, \\
& phase cycle, etc.), 16(structure, test, measure, etc.), 17(radio, \\
& frequency, communication, etc.), 18(energy, consumption, etc.), \\
& 19(sink, mobility, node, etc.), 20(real, time, etc.), 21(energy, head, \\
& cluster, etc.), 23(platform, software, hardware, etc.),25(system, \\
& vehicle, machine, etc.), 26(deployment, coverage, area, etc.), \\
& 27 (control dynamic, level, etc.), 29(human, system, body, etc.), \\
& 30 (transmission, access, layer, etc.), 31(protocol, route, path, etc.), \\
& 32 (algorithm, problem, optimization, etc.), 34(traffic, packet, delay, \\
etc.), 35(relay, code, scheme, etc.), 36(monitoring, system, etc.), & 37 (performance, evolution, simulation, etc.), 38(distribution, local \\
task, strategy, etc.) & 22 (topology, algorithm, tree, etc.) \\
\hline Negative Evolutionary Growth &
\end{tabular}

This study reveals that networking of sensor systems are growing over time (Fang et al., 2021; ClavijoRodriguez et al., 2021; Del-Valle-soto et al., 2021; Bravo-Arrabal et al., 2021; Sunny et al., 2021). Results here also suggest that wireless sensor networks have a higher rate of evolution likely because of the interaction with specific technologies, such as Internet of things, data security and monitoring system. In the context of technological applications, these sensors have a growing application in environmental monitoring and healthcare (Hassan et al., 2020; Lanzolla and Spadavecchia, 2021; Naranjo-Hernández et al., 2020; Nasser et al., 2021). A critical aspect in these sensors is the maintenance, and many sensor wireless systems are powered with batteries or self-powering technology. Ultra-low-power sensors are a desirable option because they can reduce the need for regular battery changes and support a higher technological sustainability in environment (Ari et al., 2018). Finally, technology of wireless network sensor has the advantage of easy upgrades of new technological characteristics; consequently, the technological system can be more efficient from a technological and economic point of view (Abidoye and Kabaso, 2021; Jasim et al., 2021). 


\section{- Wearable Sensor}

Figure 6 shows the top 20 words with the highest frequency in wearable sensor publications. These findings reveal that the terms "system", "device", "datum", "time", and "human" have appeared more than 6,000 times across the corpus.

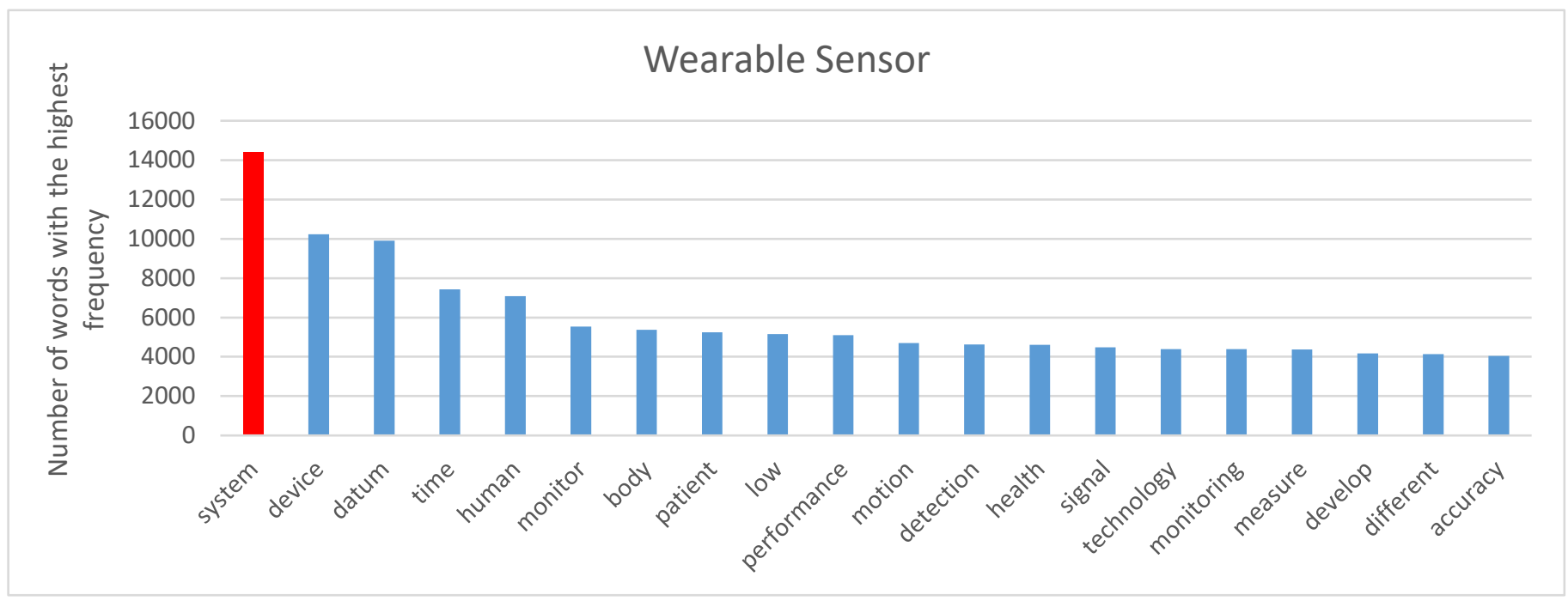

Figure 6. The highest frequent words in the wearable sensor documents

Figure 7 illustrates 22 topics of wearable sensor documents by interpreting the most important words with the highest frequency of occurrence. Each category represents contained publications. A more comprehensive insight from this analysis shows the categorizations of topics according to technological characteristics and applications of sensors. In particular, critical technological characteristics of wearable sensors are (Figure 7):

- $\quad$ sensor particles

- machine learning

- monitoring

- biosensing technologies

- pressure sensing,

- detection technologies

- $\quad$ sensor network

Instead, the application characteristics of wearable sensors are (Figure 7):

- $\quad$ energy and power

- physical activities

- medical science

- psychology 


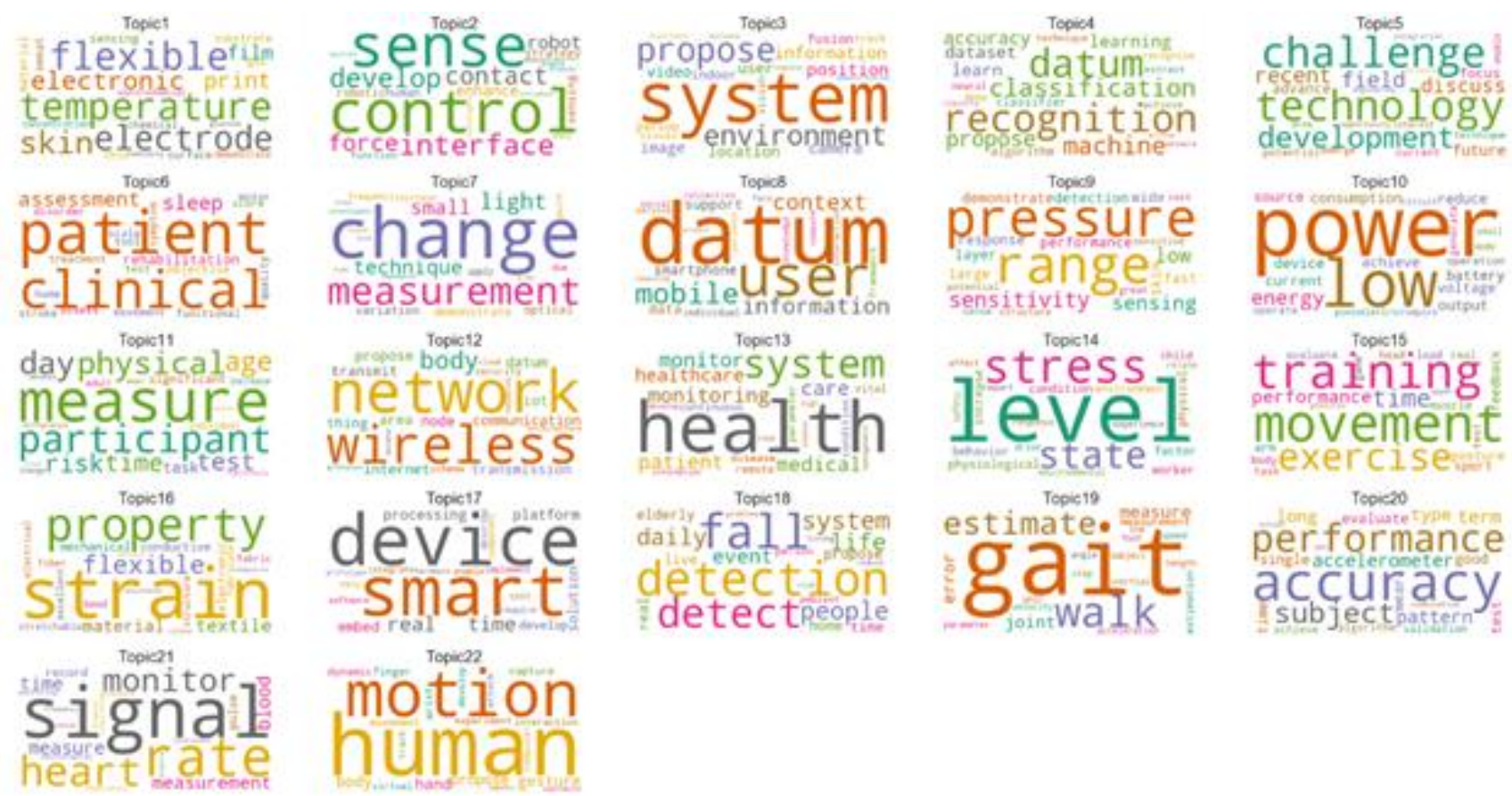

Figure 7. Word-Cloud of wearable sensor

Table 5 shows the positive popularity rate of wearable sensor technologies over time, such as sensor particles, machine learning, and pressure sensing. The growing application topics are mainly physical activities and body motion measuring.

Table 5. Dynamics of trends in wearable sensor using trend analysis

\begin{tabular}{ll}
\hline & Number of Topics \\
\hline Positive Evolutionary Growth & 1(electronic, electrode, temperature, etc.), 4(datum, recognition, machine \\
& learning, etc.), 9(pressure sensing, range, etc.), 11(measure, physical, risk, \\
& etc.), 16(strain, flexible, material, etc.) \\
& 2(sense, control, robot, etc.), 5(future, technology, challenge, etc.), 6 \\
Stable Evolutionary Growth & (patient, clinical, etc.), 7(change, measurement, etc.), 14(stress, level, etc.), \\
& 20(performance, accuracy, accelerometer, etc.), 21(signal, heart rate, etc.), \\
& 22(motion, human, etc.) \\
& 3 (environment, system, position), 8(datum, mobile, smartphone, etc.), \\
& 10(power, energy, battery), 12(wireless, network, body, etc.), 13 \\
(healthcare, system, monitoring, etc.), 17(smart, device, real-time, etc.), 18( & \\
& detection, daily, system)
\end{tabular}

This study also shows that studies on wearable sensor are growing significantly in detection and monitoring technologies. Since wearable sensors can be assumed as biosensors connected to the body, assessing different biological elements, the health care system is one of the essential applications (Chen et al., 2021; Feng et al., 2021; Kouis et al., 2021). In fact, the embedding of wearable sensor systems in health treatment procedures reduces the cost of hospitals' daily expenditures, including patient monitoring and vital sign measurement. These facilities enable doctors to remotely monitor patients' 
health conditions, reducing extended stay and hospital maintenance costs (Babu and Shantharajah, 2021; Convertino et al., 2021; Park et al., 2021). Results also suggest that pressure sensing is a main technological characteristic of wearable sensors (Lee et al., 2020; Mishra et al., 2021). However, wearable sensors are still facing several challenges. One of the most problematic issues is related to the adaptability of sensors to the body to be comfortable in body-worn devices. This study confirms that flexible, stretching, and soft technologies are growing to enable wearable devices to be more usable in daily life activities (Zhao et al., 2020). Such technologies and human motion sensing analysis studies are rising because of the importance of disabled people's living conditions enhancement, (Čuljak et al., 2020; Haque et al., 2021). In this context, results here suggest that future developments are directed to improve material flexibility, softness, and comfort of the wearable technologies (e.g., artificial legs and hands devices) to be used properly in patients (Chheng and Wilson, 2021).

\section{○ biosensors}

Figure 8 shows the 20 words with the highest occurrence across biosensors. Our findings reveal that the terms "biosensor", "detection", "base", "sensor", "surface", "cell", and "high" have the highest frequency, appearing more than 30,000 times in the corpus. These high-frequent words' similarity regarding their co-occurrence matrix have been considered in topic creations.

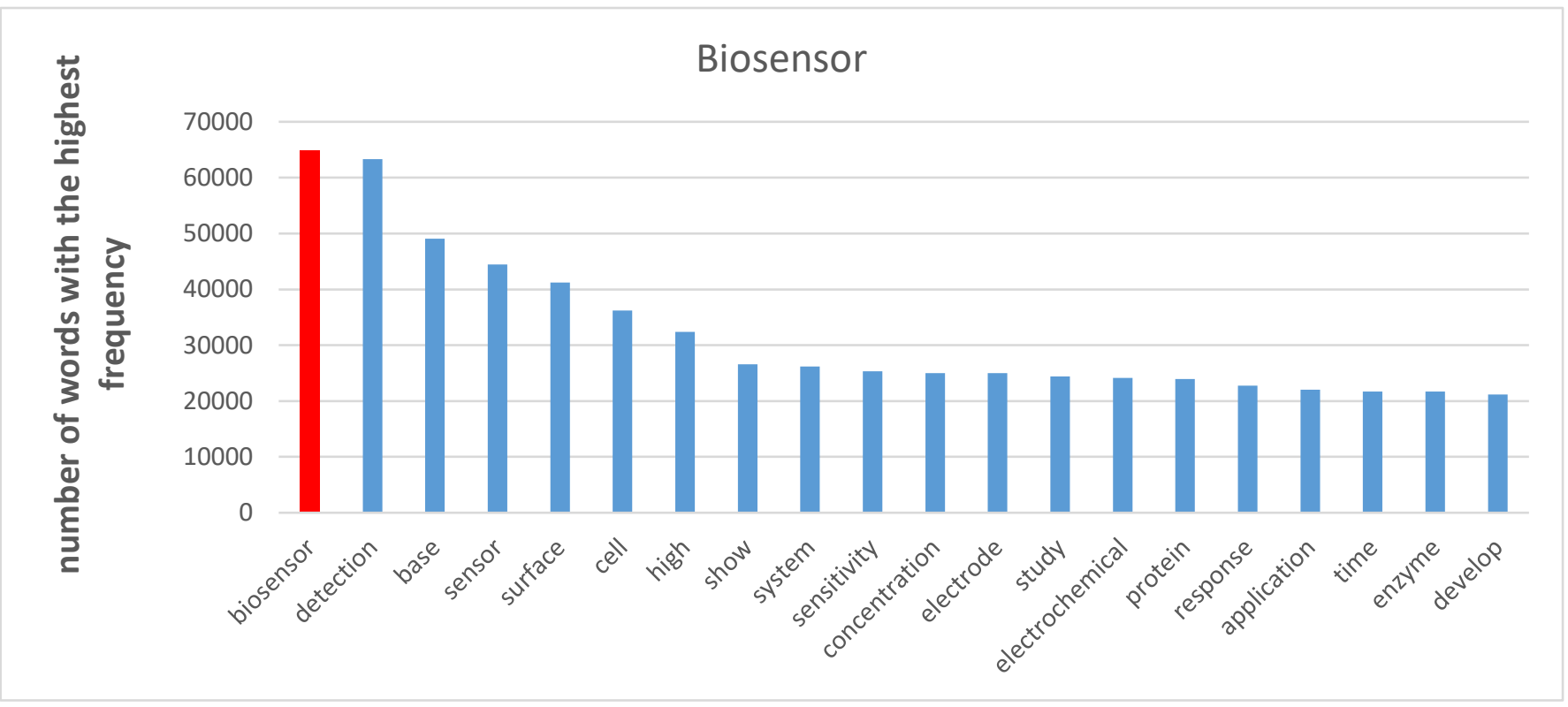

Figure 8. The highest frequent words in the biosensor network documents

Figure 9 illustrates 32 topics of biosensor documents. The largest words with the highest occurrence frequency in each category partially represent the content of the contained documents. Topics of the biosensor, visualized in figure 9 , can be also categorized in technological characteristics and applications to see technology-oriented and application-oriented aspects of this research and technological field. Main technological characteristics of biosensors are (Figure 9):

- measurement sensors

- electrochemical sensors

- detection technologies

- network sensors

- optical sensors 
- nanotechnology

- glucose sensors

Instead, main application characteristics of biosensors are (cf., Figure 9):

- genetic

- DNA sequence

- vital sign measurement

- cancer detection

- patient monitoring

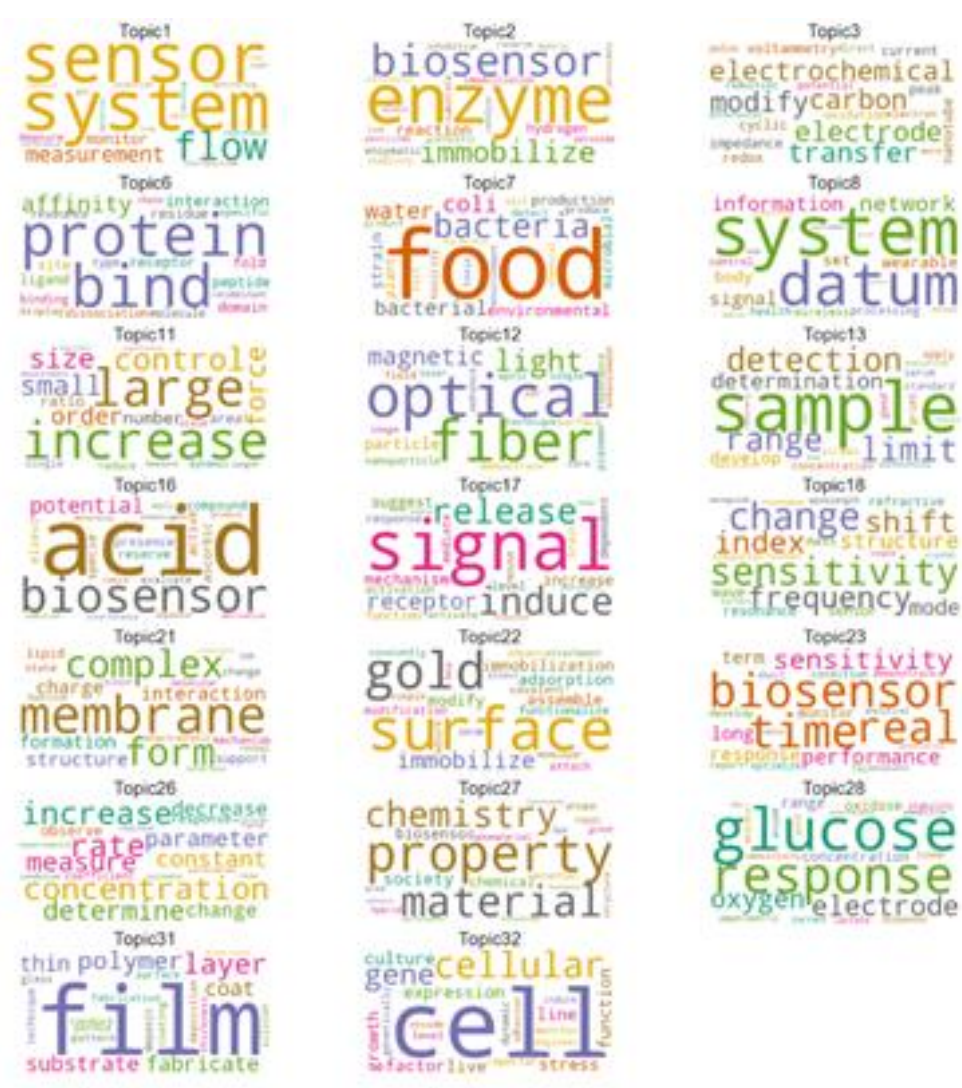

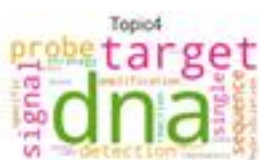

Topice

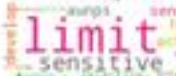

detection Topicis

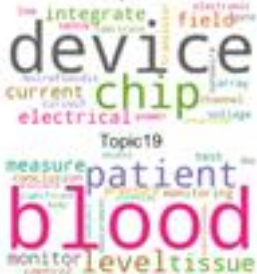
Topias

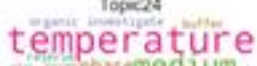

temposemedium

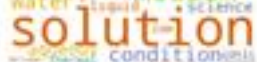

Topic29

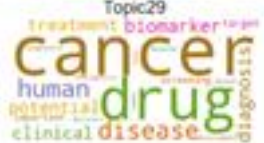

Tosies

costrapid detection carepoint low

Togkto
senergy fluorescent
i on transte at lead ion change fluorescence Tosict5

development technology -field future tosic20

piosensor biological andyty molecule rosic2s microscopy prepure nanoparticle exhibit oxide Tosicaso

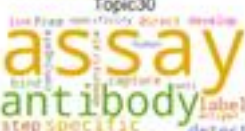

Figure 9. Cloud words of biosensor

Table 6 shows that material science, nanotechnology, and the detection process have been growing in sensor research to expand the technological aspects of biosensors. On the contrary, this analysis demonstrates that the glucose sensors topic faced a considerable reduction in its popularity. 
Table 6. Dynamics of trends in biosensor using trend analysis

\begin{tabular}{ll}
\hline Positive Evolutionary Growth & Number of Topics \\
& (chemistry, material, etc.) \\
Stable Evolutionary Growth & (sensor system, fellow, measurement, etc.), 3(electrochemical, electrode, \\
& carbon, etc.), 4(DNA, signal, etc.), 5(detection, point, etc.), 6(protein, bind, \\
& affinity, etc.), 7(food, bacterial, environment, etc.), 8(system, datum, etc.), \\
& 10(metal, fluorescence, etc.),11(size control, etc.), 12(optical fibre, \\
& magnetic, etc.), 13(detection, sample, etc.), 14(device, chip, etc.), \\
& 15(technology, development, future, etc.), 16(acid, biosensor, etc.), \\
& 17 (signal, release, etc.), 18(sensitivity, frequency, etc.), 19(patient, blood, \\
& etc.) 20(biosensor, molecule, biological, etc.),21(complex, membrane, etc.), \\
& 22 (gold, surface, etc.), 23(biosensor, real-time, sensitivity, etc.), \\
& 24 (temperature, solution, etc.), 29(cancer, drug, biomarker, etc.), 30(assay, \\
& anti-body, etc.), 31(film, layer, polymer, etc.), 32(cell, cellular, gene, etc.) \\
& 2(biosensor, enzyme, immobilize, etc.), 26(measure, parameter, \\
& concentration, etc.), 28(glucose, response, electrode, etc.)
\end{tabular}

The results here also demonstrate that biosensor studies are growing over time, especially in topics associated with detecting and monitoring applications in medical systems (Nejadmansouri et al., 2021). In fact, nanosensor technologies have started interacting with other technologies, improving the efficiency of biosensor performance to reduce human error in disease detection and the cost of human resource in the health care industry (Banerjee et al., 2021; Naresh and Lee, 2021). One of the aspects that supports the growth of biosensor is the emergence of biochemical sensors containing active materials in their chemical structures to assess biological or chemical reactions by signals generation to identify and measure the concentration of an analyte in the reaction. These technologies have been utilized mainly for detection purposes, including biomarker detection for blood, glucose level, food mass, anti-body detection, genetic aspects, etc. (Baluta et al., 2021; Holzer et al., 2021; Hong et al., 2020). We should also consider that the COVID-19 pandemic crisis has changed health systems requiring a rapid detection using immunosensor and remote patient monitoring (Mojsoska et al., 2021). In fact, one of the fundamental problems in pandemic control is the insufficient capacity of hospitals to hospitalize, at the same time, infected individuals with serious symptoms of COVID-19 (Coccia, 2021). The biosensor devices enable doctors to monitor and treat remotely patients in their house, instead of in the hospital, helping the healthcare management of patients, reducing costs and the negative effects of this novel coronavirus in society. Hence, the biosensor is gaining momentum to detect and monitor remotely COVID-19 affected patients, patients with other disorders and/or post-surgical patients to reduce the overall cost of healthcare and improve the efficiency of hospitals (cf., Ardito et al., 2021; Laghrib et al., 2021, Restrepo et al., 2021; Shahbazi et al., 2021; Stuart et al., 2021; Taha et al., 2020). 


\section{Conclusions, limitations and prospects}

This study shows that in sensor research, high growth rates are associated with research fields of wireless sensor network, wearable sensor and biosensor, supporting new directions to scientific and technological development. In particular, this study reveals that technological development of sensor is due to evolutionary pathways based on sensors having interactions with other technological systems, such as Internet of things, pervasive computing, etc. (Alharbi et al., 2021; Banerjee et al., 2021, Davoli et al., 2021; Del-Valle-soto et al., 2021; Elsisi et al., 2021; Jo et al., 2021; Kholod et al., 2021; Pal et al., 2020; Pereira et al., 2017; Wang et al., 2021). Results suggest that sensors have, as parasite technologies (Coccia and Watts, 2019), a wide spectrum of applications from health monitoring to aircraft and automotive industries (George et al., 2021; Morales et al., 2021; Zanelli et al., 2021; Zelenika et al., 2021; Zhang et al., 2021a). Moreover, the successful of smart sensors, smart objects, and cyber-physical systems are associated with the integration of the Internet of Things, through which it is possible to connect devices and exchange information among people, systems, and devices (da Costa et al., 2021). Historically, research and development (R\&D) efforts in sensor technology have been funded as an adjunct to large application programs that required sensors (National Research Council, 1995). Now, selected R\&D investments support the development of new and improved sensors with effective research planning processes directed to users for specific applications (Mee et al., 2021). The description of technological characteristics of sensors, described here, associated with performance capabilities and sensor applications in different settings can improve the allocation of R\&D investments in private and public organizations for scientific and technological development (Coccia, 2017c).

This study also shows that sensor research is a vast research field in continuous evolution because of recent advances in information and communication technologies, artificial intelligence, nanoscience, human-computer interaction, that enable intensive interactions of sensor technology with other disciplines and new technologies. Overall, then, this study maintains that growing fields in sensor research are given by wireless sensor network, wearable sensor and biosensor with new applications in environmental, sustainability and health sciences. However, these conclusions here are of course tentative. We know that other things are not equal in the dynamics of sensor research and there is need for much more detailed examinations that focus on novel sensing and interfacing technologies to explain new directions in the design, implementation, and evaluation of interactive technology of sensors in society. The future development of this study is directed to reinforce proposed results with additional data extending the empirical studies on the use of advanced intelligent sensors in ambient and pervasive computing interaction, such as smart environments, human-machine interaction and/or virtual and augmented reality.

\section{References}

1. Abidoye, A.P., Kabaso, B.2021. Energy-efficient hierarchical routing in wireless sensor networks based on fog computing. Eurasip Journal on Wireless Communications and Networking, 2021(1),8

2. Alharbi, M.A., Kolberg, M., Zeeshan, M. 2021.Towards improved clustering and routing protocol for wireless sensor networks, Eurasip Journal on Wireless Communications and Networking 2021(1),46

3. Ardito L., Coccia M., Messeni Petruzzelli A. 2021. Technological exaptation and crisis management: Evidence from COVID-19 outbreaks. R\&D Management, vol. 51, n. 4, pp. 381-392, https://doi.org/10.1111/radm.12455

4. Ari D., Çibuk M., Ağgün F. 2018 . The Comparison of Energy Consumption of Different Topologies in Multihop Wireless Sensor Networks, 2018 International Conference on Artificial Intelligence and Data Processing (IDAP), 2018, pp. 1-5, doi: 10.1109/IDAP.2018.8620903. 
5. Aroganam, G., Manivannan, N., \& Harrison, D. 2019. Review on Wearable Technology Sensors Used in Consumer Sport Applications. Sensors (Basel, Switzerland), 19(9), 1983. https://doi.org/10.3390/s19091983

6. Babu, G.C., Shantharajah, S.P.2021. Remote health patient monitoring system for early detection of heart disease, International Journal of Grid and High Performance Computing13(2), pp. 118-130

7. Baluta, S., Lesiak, A., Cabaj, J.2020. Simple and cost-effective electrochemical method for norepinephrine determination based on carbon dots and tyrosinase, Sensors (Switzerland)20(16),4567, pp. 1-13

8. Banerjee, A., Maity, S., Mastrangelo, C.H.2021. Nanostructures for biosensing, with a brief overview on cancer detection, IoT, and the role of machine learning in smart biosensors. Sensors (Switzerland) 21(4),1253, pp. 1-34

9. Blei D. M., Ng A. Y., Jordan M. I. 2003. Latent Dirichlet Allocation. Journal of Machine Learning Research 3, pp. 9931022

10. Bravo-Arrabal, J., Fernandez-Lozano, J.J., Serón, J., Gomez-Ruiz, J.A., García-Cerezo, A.2021. Development and implementation of a hybrid wireless sensor network of low power and long range for urban environments, Sensors (Switzerland) 21(2),567, pp. 1-27

11. Chen, J., Abbod, M., Shieh, J.-S.2021. Pain and stress detection using wearable sensors and devices - a review. Sensors (Switzerland), 21(4),1030, pp. 1-18

12. Chheng, C., Wilson, D. 2021. Abnormal gait detection using wearable hall-effect sensors, Sensors (Switzerland) 21(4),1206, pp. 1-23

13. Clavijo-Rodriguez, A., Alonso-Eugenio, V., Zazo, S., Perez-Alvarez, I.2021. Software-in-loop simulation of an underwater wireless sensor network for monitoring seawater quality: Parameter selection and performance validation, Sensors (Switzerland) 21(3),966, pp. 1-25

14. Coccia M. 2015. Spatial relation between geo-climate zones and technological outputs to explain the evolution of technology. Int. J. Transitions and Innovation Systems, vol. 4, nos. 1-2, pp. 5-21, http://dx.doi.org/10.1504/IJTIS.2015.074642

15. Coccia M. 2017a. Sources of disruptive technologies for industrial change. L'industria -rivista di economia e politica industriale, vol. 38, n. 1, pp. 97-120, ISSN: 0019-7416, DOI: 10.1430/87140

16. Coccia M. 2017b. Disruptive firms and industrial change, Journal of Economic and Social Thought, vol. 4, n. 4, pp. 437-450, http://dx.doi.org/10.1453/jest.v4i4.1511

17. Coccia M. 2017c. Varieties of capitalism's theory of innovation and a conceptual integration with leadershiporiented executives: the relation between typologies of executive, technological and socioeconomic performances. Int. J. Public Sector Performance Management, Vol. 3, No. 2, pp. 148-168. https://doi.org/10.1504/IJPSPM.2017.084672

18. Coccia M. 2018. General properties of the evolution of research fields: a scientometric study of human microbiome, evolutionary robotics and astrobiology, Scientometrics, vol. 117, n. 2, pp. 1265-1283, https://doi.org/10.1007/s11192018-2902-8

19. Coccia M. 2018a. The origins of the economics of Innovation, Journal of Economic and Social Thought, vol. 5, n. 1, pp. 9-28, http://dx.doi.org/10.1453/jest.v5i1.1574

20. Coccia M. 2019. The theory of technological parasitism for the measurement of the evolution of technology and technological forecasting, Technological Forecasting and Social Change, vol. 141, pp. 289-304, https://doi.org/10.1016/j.techfore.2018.12.012

21. Coccia M. 2019a. A Theory of classification and evolution of technologies within a Generalized Darwinism, Technology Analysis \& Strategic Management, vol. 31, n. 5, pp. 517-531, http://dx.doi.org/10.1080/09537325.2018.1523385

22. Coccia M. 2019b. Why do nations produce science advances and new technology? Technology in society, vol. 59, November, n. 101124, pp. 1-9, https://doi.org/10.1016/j.techsoc.2019.03.007

23. Coccia M. 2020. The evolution of scientific disciplines in applied sciences: dynamics and empirical properties of experimental physics, Scientometrics, n. 124, pp. 451-487. https://doi.org/10.1007/s11192-020-03464-y

24. Coccia M. 2020a. Destructive Technologies for Industrial and Corporate Change. In: Farazmand A. (eds), Global Encyclopedia of Public Administration, Public Policy, and Governance. Springer, Cham, Springer Nature Switzerland AG 2020. https://doi.org/10.1007/978-3-319-31816-5_3972-1. 
25. Coccia M. 2020b. Asymmetry of the technological cycle of disruptive innovations. Technology Analysis \& Strategic Management, vol. 32, n. 12, p. 1462-1477. https://doi.org/10.1080/09537325.2020.1785415

26. Coccia M. 2020c. Fishbone diagram for technological analysis and foresight. Int. J. Foresight and Innovation Policy, Vol. 14, Nos. 2/3/4, pp. 225-247. DOI: 10.1504/IJFIP.2020.111221

27. Coccia M. 2020d. Deep learning technology for improving cancer care in Society: New directions in cancer imaging driven by artificial intelligence. Technology in society, vol. 60, February, pp. 1-11, https://doi.org/10.1016/j.techsoc.2019.101198

28. Coccia M. 2021. High health expenditures and low exposure of population to air pollution as critical factors that can reduce fatality rate in COVID-19 pandemic crisis: a global analysis. Environmental Research, vol. 199, Article number 111339, https://doi.org/10.1016/j.envres.2021.111339

29. Coccia M., Bellitto M. 2018. Human progress and its socioeconomic effects in society, Journal of Economic and Social Thought, vol. 5, n. 2, pp. 160-178, ISSN: 2149-0422, www.kspjournals.org, http://dx.doi.org/10.1453/jest.v5i2.1649.

30. Coccia M., Watts J. 2020. A theory of the evolution of technology: technological parasitism and the implications for innovation management, Journal of Engineering and Technology Management, vol. 55 (2020) 101552, S09234748(18)30421-1,https://doi.org/10.1016/j.jengtecman.2019.11.003

31. Convertino, V.A., Schauer, S.G., Weitzel, E.K., (...), Sawka, M.N., Inan, O.T. $2020 . \quad$ Wearable sensors incorporating compensatory reserve measurement for advancing physiological monitoring in critically injured trauma patients, Sensors (Switzerland) 20(22),6413, pp. 1-24

32. Čuljak, I., Vasić, Ž.L., Mihaldinec, H., Džapo, H.2020. Wireless body sensor communication systems based on UWB and IBC technologies: State-of-the art and open challenges, Sensors (Switzerland) 20(12),3587, pp. 1-32

33. da Costa, V.C.F., Oliveira, L., de Souza, J.2021. Internet of everything (IoE) taxonomies: A survey and a novel knowledge-based taxonomy, Sensors (Switzerland) 21(2),568, pp. 1-35

34. Davoli, L., Paraskevopoulos, I., Campanella, C., (...), Abrardo, A., Ferrari, G. $2021 . \quad$ Ultrasonic-based environmental perception for mobile 5g-oriented xr applicationsSensors (Switzerland) 21(4),1329, pp. 1-37

35. Del-Valle-soto, C., Mex-Perera, C., Nolazco-Flores, J.A., (...), Rosas-Caro, J.C., Martínez-Herrera, A.F.2021. A lowcost jamming detection approach using performance metrics in cluster-based wireless sensor networks. Sensors (Switzerland) 21(4),1179, pp. 1-28

36. Dosi. G. 1988. Sources, Procedures, and Microeconomic Effects of Innovation. Journal of Economic Literature, 26(3), 1120-1171. Retrieved June 15, 2021, from http://www.jstor.org/stable/2726526

37. Elsisi, M., Mahmoud, K., Lehtonen, M., Darwish, M.M.F.2021. Reliable industry 4.0 based on machine learning and IOT for analyzing, monitoring, and securing smart meters. Sensors (Switzerland), 21(2),487, pp. 1-16

38. Fan, X., Shangguan, L., Rupavatharam, S., (...), Ma, Y., Howard, R. 2021. HeadFi: Bringing intelligence to all headphones. Proceedings of the Annual International Conference on Mobile Computing and Networking, MOBICOM pp. 147-159

39. Fang, W., Zhang, W., Chen, W., (...), Ni, Y., Yang, Y. 2021. MSCR: multidimensional secure clustered routing scheme in hierarchical wireless sensor networks. Eurasip Journal on Wireless Communications and Networking 2021(1), 14

40. Fortunato S., Bergstrom C. T., Börner K., Evans J. A., Helbing D., Milojević, S., Petersen A. M., Radicchi F., Sinatra R., Uzzi B., Vespignani A., Waltman L., Wang D., Barabási A.-L. 2018. Science of science, Science, Vol. 359, n. 6379, eaao0185, DOI: $10.1126 /$ science.aao0185

41. George, U.Z., Moon, K.S., Lee, S.Q. 2021. Extraction and analysis of respiratory motion using a comprehensive wearable health monitoring system, Sensors (Switzerland) 21(4),1393, pp. 1-16

42. Göpel W., Hesse J., Zemel J.N., eds. 1989. Sensors: A Comprehensive Survey, Vol. 1. New York: VCH.

43. Haque, M.R., Imtiaz, M.H., Kwak, S.T., (...), Chang, Y.-H., Shen, X. 2021. A lightweight exoskeleton-based portable gait data collection system, Sensors (Switzerland)21(3),781, pp. 1-17

44. Hassan, S.R., Ahmad, I., Ahmad, S., Alfaify, A., Shafiq, M. 2020. Remote pain monitoring using fog computing for e-healthcare: An efficient architecture, Sensors (Switzerland) 20(22),6574, pp. 1-21

45. Heikenfeld, J., Jajack, A., Rogers, J., Gutruf, P., Tian, L., Pan, T., Li, R., Khine, M., Kim, J. and Wang, J., 2018. Wearable sensors: modalities, challenges, and prospects. Lab on a Chip, 18(2), pp.217-248. 
46. Holzer, R., Bloch, W., Brinkmann, C.2020. Minimally invasive electrochemical patch-based sensor system for monitoring glucose and lactate in the human body - a survey-based analysis of the end-user's perspective, Sensors (Switzerland), 20(20),5761, pp. 1-12

47. Hong, W., Lee, J., Lee, W.G. 2020. A dual-padded, protrusion-incorporated, ring-type sensor for the measurement of food mass and intake, Sensors (Switzerland) 20(19),5623, pp. 1-11

48. Hudec, R., Matúška, S., Kamencay, P., Benco, M.2021. A smart IoT system for detecting the position of a lying person using a novel textile pressure sensor, Sensors (Switzerland) 21(1),206, pp. 1-21

49. Hussain, Z.M. 2020. Energy-efficient systems for smart sensor communications, 2020 30th International Telecommunication Networks and Applications Conference, ITNAC 20209315030

50. Jasim, A.A., Idris, M.Y.I., Azzuhri, S.R.B., (...), Rahman, M.T., Khyasudeen, M.F.B. $2021 . \quad$ Energy-efficient wireless sensor network with an unequal clustering protocol based on a balanced energy method (EEUCB), Sensors (Switzerland), 21(3),784, pp. 1-40

51. Jiang H., M. Qiang, P. Lin 2016. A topic modelling based bibliometric exploration of hydropower research. Renewable and Sustainable Energy Reviews, 2016. 57: p. 226-237.

52. Jo, T.H., Ma, J.H., Cha, S.H. 2021. Elderly perception on the Internet of things-based integrated smart-home system. Sensors (Switzerland) 21(4),1284, pp. 1-29

53. Kashani, E.S., Roshani, S., 2019. Evolution of innovation system literature: Intellectual bases and emerging trends. Technological Forecasting and Social Change, 146, pp.68-80.

54. Kholod, I., Yanaki, E., Fomichev, D., (...), Filippov, E., Nordlund, M. 2021. Open-source federated learning frameworks for IoT: A comparative review and analysis, Sensors (Switzerland) 21(1),167, pp. 1-22

55. Kissinger, P.T., 2005. Biosensors - a perspective. Biosensors and Bioelectronics, 20(12), pp.2512-2516.

56. Kouis, P., Michanikou, A., Anagnostopoulou, P., (...), Nikolopoulos, G.K., Yiallouros, P.K.2021. Use of wearable sensors to assess compliance of asthmatic children in response to lockdown measures for the COVID-19 epidemic, Scientific Reports11(1),5895

57. Laghrib, F., Saqrane, S., El Bouabi, Y., (...), Lahrich, S., El Mhammedi, M.A.2021. Current progress on COVID-19 related to biosensing technologies: New opportunity for detection and monitoring of viruses, Microchemical Journal 160,105606

58. Lanzolla, A., Spadavecchia, M.2021. Wireless sensor networks for environmental monitoring, Sensors (Switzerland) 21(4),1172, pp. 1-3

59. Lee, J.H., Heo, J.S., Lee, K.W., (...), Kim, Y.-H., Park, S.K. 2020. Locally controlled sensing properties of stretchable pressure sensors enabled by micro-patterned piezoresistive device architecture, Sensors (Switzerland) 20(22),6588, pp. 1-12

60. Li P., Liu Y., Gao X., Li H., Gong P. 2021. Energy-efficient time and energy resource allocation in non-selfish symbiotic cognitive relaying sensor network with privacy preserving for smart city, Eurasip Journal on Wireless Communications and Networking 2021(1),48

61. Liu J., Ouyang H., Han X., Liu G. 2021. Optimal sensor placement for uncertain inverse problem of structural parameter estimation. Mechanical Systems and Signal Processing 160,107914

62. McCallum A. K. 2002. MALLET: A Machine Learning for Language Toolkit. http://mallet.cs.umass.edu. (Accessed June 2021)

63. Mee, R., Dontsov, D., Langlotz, E. 2021. Interferometric device for the in-process measurement of diameter variation in the manufacture of ultraprecise spheres. Measurement Science and Technology, 32(7),074004

64. Mifrah, S. and Benlahmar, E.H. 2020. Topic modeling coherence: A comparative study between LDA and NMF models using COVID'19 corpus. Int. J. Adv. Trends Comput. Sci. Eng, 9, pp.5756-5761.

65. Mishra, R.B., El-Atab, N., Hussain, A.M., Hussain, M.M. 2021. Recent Progress on Flexible Capacitive Pressure Sensors: From Design and Materials to Applications, Advanced Materials Technologies 6(4),2001023

66. Mojsoska, B., Larsen, S., Olsen, D.A., (...), Brandslund, I., Alatraktchi, F.A. 2021. Rapid SARS-CoV-2 detection using electrochemical immunosensor, Sensors (Switzerland) 21(2),390, pp. 1-11 
67. Morales, E.S., Dauth, J., Huber, B., Higuera, A.G., Botsch, M. 2021. High precision outdoor and indoor reference state estimation for testing autonomous vehicles. Sensors (Switzerland) 21(4),1131, pp. 1-32

68. Naranjo-Hernández, David; Reina-Tosina, Javier; Roa, Laura M.; Barbarov-Rostán, Gerardo; Aresté-Fosalba, Nuria; Lara-Ruiz, Alfonso; Cejudo-Ramos, Pilar; Ortega-Ruiz, Francisco. 2020. Smart Bioimpedance Spectroscopy Device for Body Composition Estimation. Sensors 20, no. 1: 70. https://doi.org/10.3390/s20010070

69. Naresh, V., Lee, N.2021. A review on biosensors and recent development of nanostructured materials-enabled biosensors, Sensors (Switzerland) 21(4),1109, pp. 1-35

70. Nasser, N., Khan, N., Karim, L., ElAttar, M., Saleh, K. 2021. An efficient Time-sensitive data scheduling approach for Wireless Sensor Networks in smart cities, Computer Communications 175, pp. 112-122

71. National Research Council. 1995.CHAPTER 1: INTRODUCTION TO SENSORS. Expanding the Vision of Sensor Materials. Washington, DC: The National Academies Press. doi: 10.17226/4782.

72. Nejadmansouri, M., Majdinasab, M., Nunes, G.S., Marty, J.L.2021. An overview of optical and electrochemical sensors and biosensors for analysis of antioxidants in food during the last 5 years, Sensors (Switzerland) 21(4),1176, pp. $1-50$

73. Nelson, R.R. 2008. Factors affecting the power of technological paradigms, Industrial and Corporate Change, Vol. 17, No. 3, pp.485-497.

74. Pal, S., Hitchens, M., Rabehaja, T., Mukhopadhyay, S. 2020. Security requirements for the Internet of things: A systematic approach, Sensors (Switzerland) 20(20),5897, pp. 1-34

75. Park, C., Sharafkhaneh, A., Bryant, M.S., (...), Torres, I., Najafi, B. $\quad$ 2021. Toward Remote Assessment of Physical Frailty Using Sensor-based Sit-to-stand Test, Journal of Surgical Research 263, pp. 130-139

76. Pereira, A., Pimentão, J.P., Sousa, P., Onofre, S.2017. Smart sensor data acquisition in trains, Proceedings IECON 2017 - 43rd Annual Conference of the IEEE Industrial Electronics Society 2017-January, pp. 5598-5603

77. Rahimunnisa, K., Atchaiya, M., Arunachalam, B., Divyaa, V. 2021. AI-based smart and intelligent wheelchair, Journal of Applied Research and Technology 18(6), pp. 362-367

78. Rajaravivarma, V., Yang, Y. and Yang, T., 2003, March. An overview of wireless sensor network and applications. In Proceedings of the 35th Southeastern Symposium on System Theory, 2003. (pp. 432-436). IEEE.

79. Rao N. S.V., Brooks R.R., Wu C.Q. 2018. Proceedings of International Symposium on Sensor Networks, Systemsand Security -Advances in Computing and Networking with Applications, Springer.

80. Rehurek, R. and P. Sojka. Software framework for topic modelling with large corpora. in In Proceedings of the LREC 2010 Workshop on New Challenges for NLP Frameworks. 2010. Citeseer.

81. Restrepo, M., Huffenberger, A.M., Hanson, C.W., Draugelis, M., Laudanski, K. 2021. Remote monitoring of critically-ill post-surgical patients: Lessons from a biosensor implementation trial, Healthcare (Switzerland), 9(3),343

82. Röder, M., Both, A., Hinneburg, A. 2015. Exploring the Space of Topic Coherence Measures. Proceedings of the Eighth ACM International Conference on Web Search and Data Mining.

83. Roshani S., Bagheri R., Mosleh M., Coccia M. 2021. What is the relationship between research funding and citationbased performance? A comparative analysis between critical research fields. Scientometrics. https://doi.org/10.1007/s11192-021-04077-9

84. Sahal D. 1981. Patterns of Technological Innovation. Addison-Wesley Publishing Company, Inc., Reading, MA.

85. Scharnhorst A., Börner K., Besselaar P. 2012. Models of Science Dynamics: Encounters Between Complexity Theory and Information Sciences. Springer Verlag.

86. Scopus 2021. Documents, https://www.scopus.com/ (Accessed April 2021)

87. Scopus 2021a. Scopus, Search in Start exploring, https://www.scopus.com/search/form.uri?display=basic\#basic

88. Sensors 1992. 1993 Buyer's Guide. Sensors: The Journal of Machine Perception 9(12).

89. Seymour, I., Narayan, T., Creedon, N., (...), Rohan, J.F., O'Riordan, A. 2021. Advanced solid state nanoelectrochemical sensors and system for agri 4.0 applications. Sensors, 21(9),3149 
90. Shahbazi, F., Jabbari, M., Esfahani, M.N., Keshmiri, A.2021. A computational simulation platform for designing real-time monitoring systems with application to COVID-19, Biosensors and Bioelectronics 171,112716

91. Soy, H., Toy, İ. 2021. Design and implementation of smart pressure sensor for automotive applications. Measurement: Journal of the International Measurement Confederation, 176,109184

92. Stuart, T., Cai, L., Burton, A., Gutruf, P.2021. Wireless and battery-free platforms for collection of biosignals, Biosensors and Bioelectronics 178,113007

93. Sun X., Kaur, J., Milojevic' S., Flammini A., Menczer F. 2013. Social Dynamics of Science. Scientific Reports, vol. 3 , n. 1069, pp. 1-6, doi:10.1038/srep01069.

94. Sunny, A.I., Zhao, A., Li, L., Kanteh Sakiliba, S.2021. Low-cost IoT-based sensor system: A case study on harsh environmental monitoring, Sensors (Switzerland) 21(1),214, pp. 1-12, Sensors (Switzerland), 20(14),3944, pp. 1-7

95. Suresh Kumar, V., Krishnamoorthi, C.2021. Development of electrical transduction based wearable tactile sensors for human vital signs monitor: Fundamentals, methodologies and applications. Sensors and Actuators, A: Physical 321,112582

96. Taha, B.A., Mashhadany, Y.A., Mokhtar, M.H.H., Zan, M.S.D.B., Arsad, N. $\quad 2020 . \quad$ An analysis review of detection coronavirus disease 2019 (Covid-19) based on biosensor application, Sensors (Switzerland) 20(23),6764, pp. 1-29

97. Tatiparthi, S.R., De Costa, Y.G., Whittaker, C.N., (...), Zhong, R.Y., Zhuang, W.-Q.2021. Development of radiofrequency identification (RFID) sensors suitable for smart-monitoring applications in sewer systems, Water Research 198,11710

98. Teng X.F., Zhang, Y.T., Poon, C.C. and Bonato, P., 2008. Wearable medical systems for p-health. IEEE reviews in Biomedical engineering, 1, pp.62-74.

99. Turner A.P., 2013. Biosensors: sense and sensibility. Chemical Society Reviews, 42(8), pp.3184-3196.

100. Wang, G., Liu, Y., Chen, X., (...), Ma, C., Zhang, J. 2021.Power transformer fault diagnosis system based on Internet of Things, Eurasip Journal on Wireless Communications and Networking 2021(1),21

101. Wang, L., Zhang, M., Yang, B., (...), Song, S., Nie, J. 2021a. Flexible, Robust, and Durable Aramid Fiber/CNT Composite Paper as a Multifunctional Sensor for Wearable Applications, ACS Applied Materials and Interfaces 13(4), pp. 5486-5497

102. Yaqoob, U., Younis, M.I. 2021. Chemical gas sensors: Recent developments, challenges, and the potential of machine learning - a review. Sensors, 21(8),2877

103. Yick, J., Mukherjee, B. and Ghosal, D., 2008. Wireless sensor network survey. Computer networks, 52(12), pp.2292-2330.

104. Zanelli, F., Castelli-Dezza, F., Tarsitano, D., (...), Bacci, M.L., Diana, G.2021. Design and field validation of a low power wireless sensor node for structural health monitoring, Sensors (Switzerland) 21(4),1050, pp. 1-17

105. Zelenika, S., Hadas, Z., Bader, S., (...), Velagić, J., Vrcan, Ž.2020. Energy harvesting technologies for structural health monitoring of airplane components - a review, Sensors (Switzerland) 20(22),6685, pp. 1-57

106. Zhang, H., Liu, D., Lee, J.-H., (...), Yang, J., Kim, J.-K.2021. Anisotropic, Wrinkled, and Crack-Bridging Structure for Ultrasensitive, Highly Selective Multidirectional Strain Sensors. Nano-Micro Letters, 13(1),122

107. Zhang, X., Zhao, Z., Wang, Z., Wang, X. 2021a. Fault detection and identification method for quadcopter based on airframe vibration signals, Sensors (Switzerland) 21(2),581, pp. 1-16

108. Zhao, S., Liu, J., Gong, Z., (...), Chan, C.C., Ruan, S. 2020. Wearable physiological monitoring system based on electrocardiography and electromyography for upper limb rehabilitation training, Sensors (Switzerland) 20(17),4861, pp. 1-17 